\title{
Versioned Genbank Accession Number
}

National Cancer Institute

\section{Source}

National Cancer Institute. Versioned Genbank Accession Number. NCI Thesaurus. Code C45814.

A Genbank accession number with an explicit version. 